Malchow, Morbus Crohn 

Helmut Malchow

\section{Morbus Crohn}

Ein Ratgeber für Patienten und ihre Angehörigen

unter Mitarbeit von A. Kiss, Wien

Walter de Gruyter

Berlin · New York 1990 
Prof. Dr. med. Helmut Malchow

Städtisches Krankenhaus

Zentrum für Innere Medizin

Medizinische Klinik II

Dhünnberg 60

D-5090 Leverkusen 1

Dr. A. Kiss, 1. Med. Universitätsklinik, Wien, Lazarettgasse 14, verfaßte Kapitel 11.

Das Buch enthält 19 Abbildungen.

Zeichnungen von Helmut Holtermann, Berlin.

CIP-Titelaufnahme der Deutschen Bibliothek

Malchow, Helmut:

Morbus Crohn : ein Ratgeber für Patienten und ihre Angehörigen / Helmut Malchow. Unter Mitarb. von A. Kiss. [Zeichn. von Helmut Holtermann]. - Berlin : New York : de Gruyter, 1990

ISBN 3-11-012449-1

(C) Copyright 1990 by Walter de Gruyter \& Co., Berlin 30.

Alle Rechte, insbesondere das Recht der Vervielfältigung und Verbreitung sowie der Übersetzung, vorbehalten. Kein Teil des Werkes darf in irgendeiner Form (durch Photokopie, Mikrofilm oder ein anderes Verfahren) ohne schriftliche Genehmigung des Verlags reproduziert oder unter Verwendung elektronischer Systeme verarbeitet, vervielfältigt oder verbreitet werden.

Printed in Germany.

Der Verlag hat für die Wiedergabe aller in diesem Buch enthaltenen Informationen (Programme, Verfahren, Mengen, Dosierungen, Applikationen etc.) mit Autoren bzw. Herausgebern große Mühe darauf verwandt, diese Angaben genau entsprechend dem Wissensstand bei Fertigstellung des Werkes abzudrucken. Trotz sorgfältiger Manuskripterstellung und Korrektur des Satzes können Fehler nicht ganz ausgeschlossen werden. Autoren bzw. Herausgeber und Verlag übernehmen infolgedessen keine Verantwortung und keine daraus folgende oder sonstige Haftung, die auf irgendeine Art aus der Benutzung der in dem Werk enthaltenen Informationen oder Teilen davon entsteht.

Die Wiedergabe von Gebrauchsnamen, Handelsnamen, Warenbezeichnungen und dergleichen berechtigt nicht zu der Annahme, daß solche Namen ohne weiteres von jedermann benutzt werden dürfen. Vielmehr handelt es sich häufig um gesetzlich geschützte, eingetragene Warenzeichen, auch wenn sie nicht eigens als solche gekennzeichnet sind.

Satz: Arthur Collignon GmbH. - Druck: Gerike GmbH, Berlin. - Bindung: Lüderitz \& Bauer GmbH, Berlin. 